\title{
Sex chromosome composition revealed in Characidium fishes (Characiformes: Crenuchidae) by molecular cytogenetic methods
}

\author{
Marlon F. Pazian, Claudio Oliveira \& Fausto Foresti \\ Laboratório de Biologia e Genética de Peixes, Departamento de Morfologia, Instituto de Biocięncias, Universi- \\ dade Estadual Paulista (UNESP), Distrito de Rubião Júnior S/N, Botucatu, SP, CEP 18618-000, Brasil; e-mail: \\ marlon_pazian@hotmail.com
}

\begin{abstract}
The W chromosome of the fishes Characidium cf. fasciatum, Characidium sp. and Characidium cf. gomesi is heterochromatic, as is usually seen in most Characidium species. Samples of W-chromatin were collected by mechanical microdissection and amplified by DOP-PCR (degenerate oligonucleotide-primed polymerase chain reaction), to be used as painting probes ( $\mathrm{DCg}$ and $\mathrm{CgW}$ ) and for sequence analysis. FISH (fluorescence in situ hybridization) with DCg probe painted the whole $\mathrm{W}$ chromosome, the pericentromeric region of $\mathrm{Z}$ chromosomes and the terminal region of $\mathrm{B}$ chromosomes. DOP-PCR-generated fragments were cloned, sequenced and tested by in situ hybridization, but only CgW4 produced positive hybridization signals. Clone sequence analysis recovered seven distinct sequences, of which six did not reveal any similarity to other known sequences in the GenBank or GIRI databases. Only CgW9 clone sequence was recognized as probably derived from a Helitron-transposon similar to that found in the genome of the zebrafish Danio rerio. Our results show that the composition of Characidium's W chromosome does seem rich in repetitive sequences as well as other W chromosomes found in several species with a ZW sex-determining mechanism.
\end{abstract}

Key words: fish; W chromosome paint; repetitive DNA; female heterogamety

\section{Introduction}

In many species of vertebrates sex determination is linked to heterogametic sex chromosomes in males (e.g., most mammals, XY) or females (e.g., birds, snakes, some amphibians, ZW). Fishes, however, express all possible forms of sex determination systems somehow associated with the huge biodiversity levels observed among them (reviewed in Volff et al. 2007). In the particular case of Neotropical fishes, female heterogamety was reported in Characidium Reinhardt, 1867 and Parodon genera Valenciennes, 1850 (e.g., Vicente et al. 2003; Vicari et al. 2008; Machado et al. 2011), male heterogamety was found in, e.g., Hoplias malabaricus (Bloch, 1794) (Cioffi et al. 2011, 2012), and other species have multiple sex chromosomes, such as Leporinus elongatus Valenciennes, 1850 (Parise-Maltempi et al. 2007) or Harttia carvalhoi Miranda Ribeiro, 1939 (Cioffi et al. 2012) among others. Despite the differences in sex chromosome determination, these chromosomes share some features: $\mathrm{Y}$ and $\mathrm{W}$ are mostly heterochromatic while $\mathrm{X}$ and $\mathrm{Z}$ usually have more euchromatic regions. The build-up of heterochromatin and gene inactivation in $\mathrm{Y}$ and $\mathrm{W}$ chromosomes are considered converging properties in the process of sex chromosome differentiation (Takehana et al. 2012).

Given the diversity of sex determination systems, fishes are considered good models for studying sex chromosomes since species with less differentiated sex chro- mosomes are also included (Volff et al. 2007). The genus Characidium is composed of species with clearly differentiated ZW sex chromosomes and species with homomorphic chromosomes, i.e. no morphological differentiation is perceptible by cytogenetic methods. The species Characidium cf. gomesi Travassos, 1956 has clearly differentiated $\mathrm{Z}$ and $\mathrm{W}$ chromosomes, with heterochromatin occupying most of the $\mathrm{W}$ chromosome but only the pericentromeric region of the $\mathrm{Z}$ chromosome, becoming easily distinguishable from the autosomes (Vicari et al. 2008; Pansonato-Alves et al. 2011; Machado et al. 2011). While heterochromatin is known to be rich in repetitive DNA (e.g., Charlesworth et al. 2005; Volff et al. 2007), the identification and characterization of repetitive DNAs specific to sex chromosomes has also been performed in fishes (Parise-Maltempi et al. 2007; Takehana et al. 2012). However, no known function has been attributed to these sequences in fishes or in any other group of organisms where they were described.

In the present study seven sequences $(\mathrm{CgW})$, derived from the $\mathrm{W}$ chromosome of Characidium cf. gomesi (DCg), were isolated and characterized, make know their composition, structure and possibly the mechanisms underlying the origin and evolution of sex chromosomes in the genus Characidium. All sequences were characterized for their molecular composition and chromosome distribution by FISH in specimens from three distinct populations of $C$. cf. gomesi, C. cf. fasciatum Reinhardt, 1866 and Characidium sp. Only the 
Table 1. Sampling sites of the Characidium species analysed. Information on the total number and sex of the specimens sampled is given.

\begin{tabular}{|c|c|c|c|c|}
\hline Species & no. + sex of specimens & Sampling site & Basin & Coordinates \\
\hline C. cf. fasciatum & $1 q$ & Rio sem nome (MG) & Rio São Francisco & $19^{\circ} 8^{\prime} 18.50^{\prime \prime} \mathrm{S}, 44^{\circ} 07^{\prime} 17.60^{\prime \prime} \mathrm{W}$ \\
\hline Characidium sp. & $5 \stackrel{+}{\oplus}, 3 \bigcirc^{r}$ & Rio Formoso (GO) & Alto Rio Paraná & $18^{\circ} 16^{\prime} 17.00^{\prime \prime} \mathrm{S}, 52^{\circ} 50^{\prime} 34.40^{\prime \prime} \mathrm{W}$ \\
\hline C. cf. gomesi & $9 \stackrel{9}{+}, 5 \bigcirc$ & Rio da Cachoeira (GO) & Alto Rio Paraná & $18^{\circ} 34^{\prime} 50.80^{\prime \prime} \mathrm{S}, 52^{\circ} 05^{\prime} 52.80^{\prime \prime} \mathrm{W}$ \\
\hline C. cf. gomesi & $3 \stackrel{+}{+}$ & Córrego Águas da Magdalena (SP) & Alto Rio Paraná & $22^{\circ} 59^{\prime} 26.28^{\prime \prime} \mathrm{S}, 48^{\circ} 68^{\prime \prime} \mathrm{W}$ \\
\hline C. cf. gomesi & $4 \stackrel{+}{\oplus}, 1 \bigcirc^{r}$ & Córrego Alambari (SP) & Alto Rio Paraná & $22^{\circ} 00^{\prime \prime} \mathrm{S}, 48^{\circ} 00^{\prime \prime} \mathrm{W}$ \\
\hline
\end{tabular}

Explanations: Brazilian states: MG - Minas Gerais; GO - Goiás; SP - São Paulo.

CgW4 distribution could be resolved and only in $C$. cf. gomesi (specimens from the Alambari stream), demonstrating almost full coverage of the $\mathrm{W}$ chromosome, the pericentromeric region of the $\mathrm{Z}$ chromosomes and $\mathrm{B}$ chromosomes, whenever present (specimens from the Águas da Magdalena stream). The DCg probe on the other hand, although displaying the same coverage as probe $\mathrm{CgW} 4$, also showed positive signals in the other species tested.

\section{Material and methods}

\section{Sampling}

A total of 31 Characidium sp. individuals was collected in the Brazilian river basins of Alto Paraná and São Francisco (Table 1). Specimens were sacrificed after an overdose of anaesthesia (benzocaine), fixed in $10 \%$ formalin and preserved in $70 \%$ ethanol for identification and deposition in the ichthyologic collection of the Laboratório de Biologia e Genética de Peixes, UNESP (SP, Brazil).

Cytogenetic analysis

Chromosome suspensions were obtained from standard kidney preparations (Foresti et al. 1981) and C-banding was performed following Sumner (1972) with some modifications. Chromosome microdissection of the $\mathrm{W}$ chromosome from one specimen of Characidium cf. gomesi collected in the Alambari stream (Table 1) and subsequent probe preparation by DOP-PCR (DCg probe) followed Pazian et al. (2013). From this probe, seven fragments $(\mathrm{CgW})$ were isolated from agarose gel, cloned and also used as FISH probes [ $\sim 700 \mathrm{ng}$ probe/hybmix ( $50 \%$ formamide, $10 \%$ dextran sulphate, 2x SSC) per slide, $18 \mathrm{~h}, 37^{\circ} \mathrm{C}$ ] (Pinkel et al. 1986). Signal detection was performed with antidigoxigenin-rhodamine (Roche) and DAPI counterstaining in Vectashield ${ }^{\circledR}$ anti-fading medium. Preparations were observed under an Olympus BX61 and images were recorded using Image Pro Plus 6.0 software (Media Cybernetics).

\section{Molecular analysis}

The $\mathrm{CgW}$ fragments derived from the $\mathrm{DCg}$ probe were inserted into a pGEM ${ }^{\circledR}$ T Easy Vector System (Promega) and cloned into Escherichia coli DH5 $\alpha$ Escherich, 1885 competent cells following the manufacturer's instructions. Sequence analyses were performed in an ABI 3130 DNA Analyzer (Applied Biosystems) using the Big Dye ${ }^{\mathrm{TM}}$ Terminator v.3.1 Cycle Sequencing Ready Reaction (Applied Biosystems, Inc.) and the universal pair of primers M13 (F 5'-AGC GGA TAA CAA TTT CAC ACA GG-3' and $\mathrm{R}$ 5'-CCC AGT CAC GAC GTT GTA AAA CG3'). Seven distinct sequences were retrieved (Table 2; access number CgW1 - kj160173, CgW2 - kj160174, CgW4 - kj160175, CgW9 - kj160176, CgW10 - kj160177,
CgW13 - kj160178, CgW34 - kj160179), edited using BioEdit (http://www.mbio.ncsu.edu/bioedit/bioedit.html) and blasted against sequences deposited in GenBank (http://www.ncbi.nlm.nih.gov/blast/) and GIRI (http:// www.girinst.org/censor/index.php) databases for similarity searches.

The inserts further amplified using the M13 pair of primers in a PCR mix containing $0.5 \mu$ l of each primer $(10 \mu \mathrm{M}), 3.0 \mu \mathrm{l}$ of dATP, dCTP and dGTP $(2 \mathrm{mM}), 0.7 \mu \mathrm{l}$ of dTTP $(2 \mathrm{mM}), 0.6 \mu \mathrm{l}$ of digoxigenin - $11 \mathrm{dUTP}$ (Roche), $5 \mu \mathrm{l}$ of buffer $(10 \mathrm{X}), 1.5 \mu \mathrm{l}$ of $\mathrm{MgCl}_{2}(50 \mathrm{mM}), 1.0 \mu \mathrm{l}$ of DNA $(\sim 50 \mathrm{ng})$ and $0.3 \mu \mathrm{l}$ of Taq $(5 \mathrm{U} / \mu \mathrm{l})$ in a final volume of $50 \mu$ l. The PCR programme consisted of an initial step of $5 \mathrm{~min}$ at $94^{\circ} \mathrm{C}, 35$ cycles of $1 \mathrm{~min}$ at $95^{\circ} \mathrm{C}, 1 \mathrm{~min}$ at $50^{\circ} \mathrm{C}$ and $1.5 \mathrm{~min}$ at $72^{\circ} \mathrm{C}$, and a final extension step of 7 min at $72^{\circ} \mathrm{C}$. The seven fragments isolated were mapped in the analysed specimens; only $\mathrm{CgW} 4$ showed hybridization signals in C. cf. gomesi from the Alambari and Águas da Magdalena streams.

\section{Results}

All specimens were characterized by $2 n=50$ chromosomes (metacentric/submetacentric) (Fig. 1) except for populations of Characidium cf. gomesi from the Águas da Magdalena stream, which also evidenced up to 2 supernumerary B chromosomes (Fig. 2). C-banding was restricted to the centromeres of autosomes and accumulated in the sex chromosomes covering the majority of the $\mathrm{W}$ chromosome and the pericentromeric region of the $\mathrm{Z}$ chromosome, as expected (e.g., Vicari et al. 2008; Machado et al. 2011; Pazian et al. 2013). This method allowed us to identify the sex chromosomes and B chromosomes and distinguish them from autosomes (Figs 2, $3)$.

FISH with the DCg probe revealed hybridization signals dispersed along the whole $\mathrm{W}$ chromosome and the pericentromeric region of the $\mathrm{Z}$ chromosome of all Characidium specimens analysed in this study, both males and females (Fig. 1). Additionally, in specimens from the Águas da Magdalena stream, positive hybridization signals were also found interstitially in $\mathrm{B}$ chromosomes (Figs 2B-D).

The seven $\mathrm{CgW}$ fragment sequences were characterized by a predominance of $\mathrm{A}$ and $\mathrm{T}$ nucleotide bases (57-71\%; Table 2). No similarity to any other sequence already deposited in GenBank was found (Table 3). However, in the GIRI database the sequence of CgW9 revealed about $73 \%$ similarity to the transposon Helitron present in the genome of Danio rerio (Hamilton, 


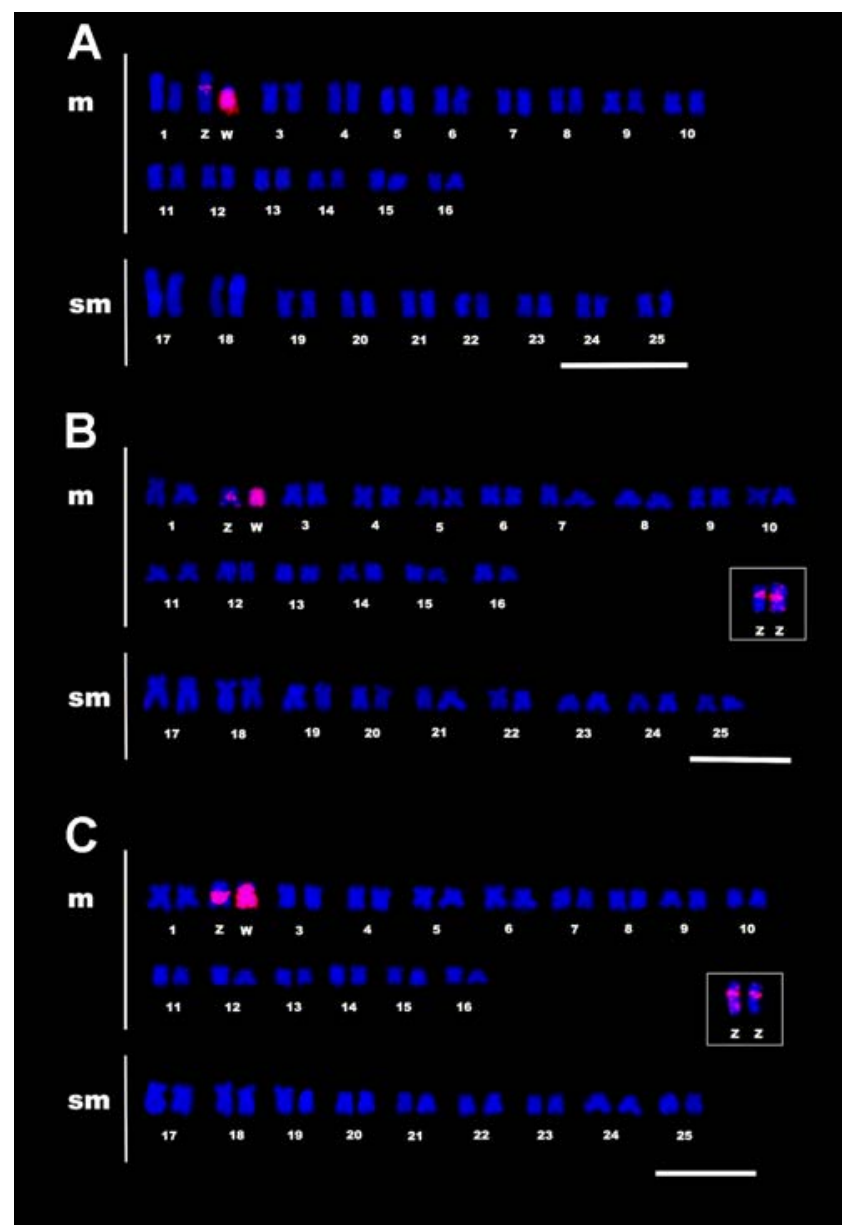

Fig. 1. Karyotype of female specimens (A) C. cf. fasciatum, (B) Characidium sp. and (C) C. cf. gomesi after in situ hybridization with $\mathrm{DCg}$ probe (in red). Inset of sex chromosomes Z-bearing chromosome pair. Scale $10 \mu \mathrm{m}$.

1822). The remaining sequences demonstrated no positive match in any of the databases.

From all seven, only fragment CgW4 showed positive hybridization signals. It also hybridized to the $\mathrm{W}$ and $\mathrm{Z}$ chromosomes in a similar pattern to the results with the DCg probe (Fig. 2), i.e., dispersed over most the $\mathrm{W}$ chromosome and in the pericentromeric region of the $\mathrm{Z}$ chromosome. Comparing two populations of the same species $C$. cf. gomesi, positive hybridization signals were also detected in the $\mathrm{B}$ chromosomes of the population from the Águas da Magdalena stream (Pardo River) (Figs 2B, D). However, when CgW4 was hybridized to the other two species and in specimens of $C$. cf. gomesi from the Rio da Cachoeira stream, no hybridization signals were perceptible.

\section{Discussion}

The repetitive nature of the $W$ chromosomes

of Characidium sp.

The vast study of non-coding repetitive DNAs has demonstrated the importance of these sequences in the structural and functional organization of the genome (Schueler et al. 2001; Biémont \& Vieira 2006). A

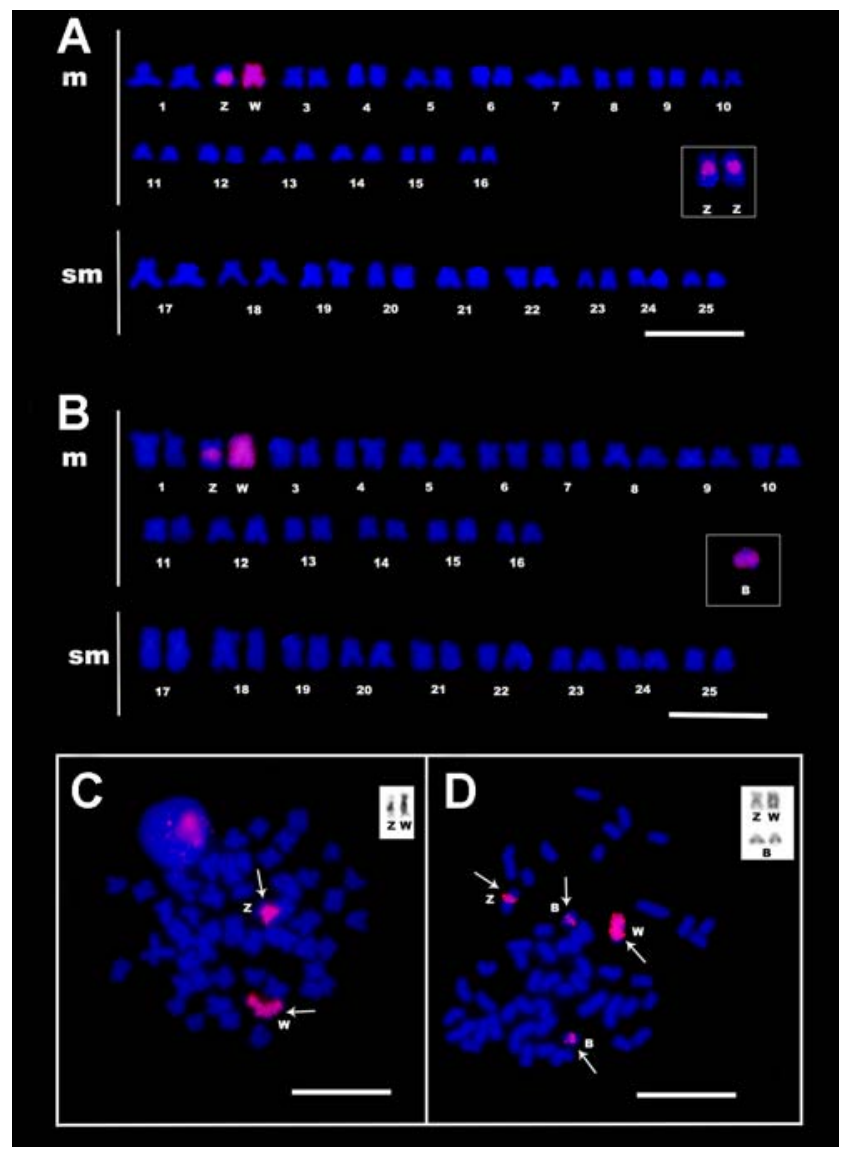

Fig. 2. Karyotype and somatic metaphase plates of females Characidium cf. gomesi from (A, C) córrego Alambari and (B, D) córrego Águas da Magdalena (bottom panel) showing the hybridization patterns (in red) of probes (A, B) DCg and (C, D) CgW4. Chromosomes are counterstained by DAPI. Sex chromosomes $\mathrm{Z}$ and $\mathrm{W}$ and supranumerary chromosomes $\mathrm{B}$ are indicated by arrows and included inset after C-banding. Scale $10 \mu \mathrm{m}$.

clear correlation between these sequences and sex chromosomes has been established by numerous studies (e.g., Nanda et al. 1990, 2000; Matsubara et al. 2006; Kejn̄ovsky et al. 2009) including several Neotropical fish groups (e.g., Parise-Maltempi et al. 2007; Cioffi et al. 2011, 2012; Machado et al. 2011), suggesting that the differentiation of sex chromosomes' mechanism is often associated with the accumulation of repetitive DNA. Accordingly, repetitive sequences represent a powerful tool to elucidate both the processes of morphological differentiation of sex chromosomes in fishes and to possibly understand some of the diversity of the differentiation systems observed in this group of vertebrates (Cioffi et al. 2011).

Different types of repetitive DNAs have been associated to sex chromosomes, somehow relating to the diversity of genomes and evolutionary pathways behind this differentiation in fishes, e.g., Xiphophorus maculatus (Günther, 1866) (Nanda et al. 2000; Zhou et al. 2006) and Hoplias malabaricus (Cioffi et al. 2011). For example, various studies have reported the accumulation of retroelements in the sex chromosomes of several taxa (e.g., Steinemann \& Steinemann 1992; Cermak et al. 2008; Ferreira et al. 2011). This type of accumulation 
Table 2. DNA sequences of seven fragments of DCg probe derived from the W chromosome of Characidium cf. gomesi.

\begin{tabular}{|c|c|}
\hline Fragment/clone ID & DNA sequence $\left(5^{\prime} \rightarrow 3^{\prime}\right)$ \\
\hline CgW_1 & $\begin{array}{l}\text { CCCGGATGTGGCATACCTGGCAAGCCATGTTCCTTAATTAAATTTAATAATTCAGTTTTTACATAG } \\
\text { TCACAGCTGCGTTTCAAAATAGAACGAGAATCTACGTAACGGTAATTGTGCATCAAGAAAGCAGG } \\
\text { AATACGTAGTGTACCAGTTGGTAAGCCTTTACAGGATCAATATTTTCATAGTTGTAATCCACGAA } \\
\text { CCAGTTT }\end{array}$ \\
\hline CgW_2 & $\begin{array}{l}\text { GCTTTATGTGGGCTTGCTCTCGCTACTAGCCAGTAAACCATCTGCATTTGATAATAATGCCATTTA } \\
\text { TTTATTCATTGGCTATCAATACCCAAAACAAATAAATTATTTAGATCTTACAAAAGCCCCGCATCT } \\
\text { TATTAGTGGCAGGCCGCTCAAAGGAGACGATTACTAAAATGTGCACACCTTAATGGTGAGTATC } \\
\text { TTAATGCA }\end{array}$ \\
\hline CgW_4 & $\begin{array}{l}\text { GTTCCATGTGGGAGATGTAAATGTGACTGTAGATTAAACTTTAGTAGTTCTTAGAAGCACTAACA } \\
\text { TAGACACAGCATAGATATACACATTGAAAAGTCTGTATGTGTTGGATGCCACATAATGTACTCGAG } \\
\text { TCGGA }\end{array}$ \\
\hline CgW_9 & $\begin{array}{l}\text { GCTTCATGTGGTTGCTACATCGTTGCTAAGTAGATGCTATATCGATGCTAAGTGGATGCTATATC } \\
\text { ATTGCTAAGTGGATGCTACATGGCTGCTACATCGTTGGTTAGTGGATGATACATGGTTGCTATGA } \\
\text { GGTTGCTTAGTGGATGCTATATTGTTGCTAAGTGGCTGCTACATCATTGCTAAGTGGATGCTACA } \\
\text { TGGCTACTA }\end{array}$ \\
\hline CgW_10 & $\begin{array}{l}\text { GCATTATGTGGATTAATGAGCTGAACTAGAGAATAAAAAGTTTAAAAAGAATAAAAGAATAGCTT } \\
\text { TGAAGTTAGTGCAAGCATATATTCTTTAATCTAAATCATTTAATCTTTCCTATGAATAAAAATCTT } \\
\text { AATACATTATAATCGACCACATACAACGCTCGAGTCGG }\end{array}$ \\
\hline CgW_13 & $\begin{array}{l}\text { GAGACATGTGGGTAAGTAGATCTTCTATCAAGAAAATTTTTAATTTTTTACTGTATGTGAAGTTT } \\
\text { TTAATTACGTTTTCTGCCTGTGTTTCTGCTGTTGCCACATTTGGAACTCGAGTCG }\end{array}$ \\
\hline CgW_34 & $\begin{array}{l}\text { TTATCATGTGGATATTTAACATTTCTTCCTTCTAGGTGCCTATGACAAACATTTGCCTTTTGTCC } \\
\text { TGATGGGTAGTCTCACAGTTCTCGTGGGTATTTTTACCTTGTTTCTCCCAGAAATCTATAATATG } \\
\text { CCTTTGCCAGATACAATTGAAGAGATACTGAGAGTAAAAGGGAAATGTTTAGGTTGTTTT } \\
\text { TAGTTTCCTTTGGTCGTTCTTTTTCGTCTGTGTTCGTATGCCACATAACGTCCTCGAGTCGGAA }\end{array}$ \\
\hline
\end{tabular}

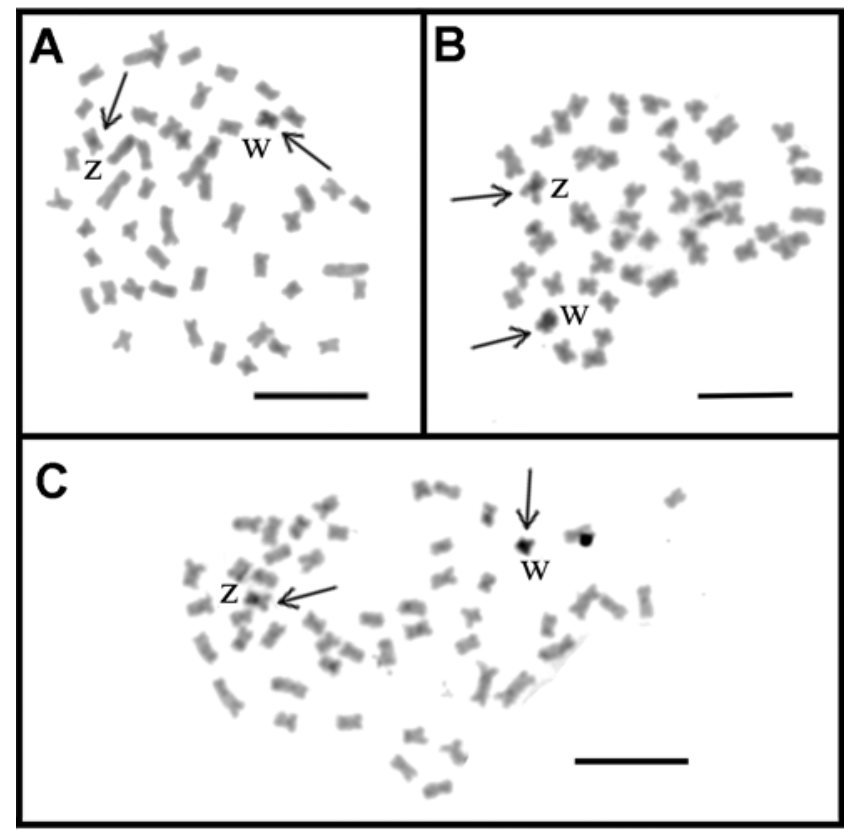

Fig. 3. Somatic metaphase plates of female specimens (A) C. cf. fasciatum, (B) C. cf. gomesi and (C) Characidium sp. after $\mathrm{C}$-Banding. Arrows indicate $\mathrm{Z}$ and $\mathrm{W}$ chromosomes. Scale $10 \mu \mathrm{m}$.

would greatly affect gene activity and could therefore be considered a major step towards the morphogenesis of sex chromosomes (e.g., Steinemann \& Steinemann 1992).

In the present study, the characterization of seven fragments ( $\mathrm{CgW})$ derived from the $\mathrm{W}$ chromosome (DCg probe) consist mostly of repetitive sequences as confirmed after C-banding and FISH results (Figs 1-
3 ). On the other hand, not only do sex repetitive sequences evolve faster and independently but also often they become species-specific (Charlesworth et al. 2005). Notwithstanding, blast analyses in a database of repetitive DNA elements (http://www.girinst.org/repbase/) resulted in $\mathrm{CgW} 9$ revealing relatively high homology $(\sim 73 \%)$ to a retrotransposon described in a fish genome (Table 3). Even though it was not possible to map this fragment in the chromosomes of the Characidium species analysed, this result supports the association of retroelements with the sex chromosomes of at least $C$. cf. gomesi, the species from which the probe was derived.

W Chromosome-specific sequences in Characidium sp. The seven fragments derived from the W chromosomespecific probe (DCg) of $C$. cf. gomesi did not reveal any similarity among themselves or with any sequences deposited in GenBank to date (Table 3). This kind of dead-end result has been reported before when studying sequences present in the sex chromosomes of Leporinus elongatus (Nakayama et al. 1994; Parisi-Maltempi et al. 2007), Parodon hilarii Reinhardt, 1866 (Vicente et al. 2003), Cydia pomonella L., 1758 (Fuková et al. 2007) and Oryzias hubbsi Roberts, 1998 (Takehana et al. 2012), for example. Of the seven distinct fragments analysed, only CgW9 evidenced similarity $(\sim 73 \%)$ to a DNA transposon (Helitron-2 Dr) isolated from the genome of Danio rerio. Likewise, several Helitrons have been assigned to the sex chromosomes of Xiphophorus maculatus (Zhou et al. 2006), Takifugu rubripes (Temminck \& Schlegel, 1850) or even Danio rerio (Poulter et al. 2003).

On the other hand, only the CgW4 probe was 
Table 3. Characterization of seven fragments derived from the DCg probe and blast results against GenBank and GIRI databases.

\begin{tabular}{|c|c|c|c|c|}
\hline Fragment/clone ID & GenBank (\% similarity) & GIRI ( $\%$ similarity) & $\% \mathrm{GC}$ & $\% \mathrm{AT}$ \\
\hline CgW_1 & 0 & 0 & 38.2 & 61.8 \\
\hline CgW_2 & 0 & 0 & 37.8 & 62.2 \\
\hline CgW_4 & 0 & 0 & 37.5 & 62.5 \\
\hline CgW_9 & 0 & 72.9 Zebrafish Helitron & 42.7 & 57.3 \\
\hline CgW_10 & 0 & 0 & 28.4 & 71.6 \\
\hline CgW_13 & 0 & 0 & 35.0 & 65.0 \\
\hline CgW_34 & 0 & 0 & 37.8 & 62.2 \\
\hline
\end{tabular}

able to yield positive hybridization signals (Fig. 2) and only in Characidium cf. gomesi, the species from which the fragments were isolated. This result suggests some kind of species-specificity supporting the hypothesis that both repetitive sequences and sex chromosomes evolve independently after species or population divergence (review in Charlesworth et al. 2005; Cioffi et al. 2011), also benefitting from the partial or total lack of recombination between homologues (Charlesworth et al. 2005). Hybridization patterns were comparable to those of the whole paint probe $\operatorname{DCg}$ (Figs 1,2) and the remaining fragments did not show any apparent signal of hybridization (not shown), probably suggesting that (1) despite its low number of nucleotides ( $136 \mathrm{bp}$; Table 2), CgW4 is highly repetitive and comprises most of the DCg probe and/or W chromosome heterochromatin; and/or (2) the remaining sequences are present in low copy numbers in the chromosomes/genome, becoming imperceptible by FISH on mitotic chromosomes. For example, the Helitron here represented by the CgW9 sequence proved a modest number of copies in the genomes of Xiphophorus maculatus and other Poecilids (less than 20 copies per genome; Zhou et al. 2006).

Previous studies have demonstrated a single origin for the sex chromosomes of some Characidium species (e.g., Vicari et al. 2008; Machado et al. 2011; Pazian et al. 2013). After events of speciation (reproductive isolation) or simply after populations' separation (geographic isolation), the sex chromosomes of each Characidium group followed an exclusive evolutionary history, resulting in morphologic differences of the sex chromosomes between Characidium species. The independent evolutionary pathways alongside the accumulation of neutral mutations and the decrease in or the total lack of crossing-over between the sex chromosomes most likely lead to amplification/deletion events and to the origin of unique chromosome-specific sequences in the sex chromosomes of each Characidium representative.

$B$ and sex chromosomes in Characidium cf. gomesi In situ hybridization with both the whole W chromosome paint DCg or the fragment CgW4 evidenced positive signals in the $\mathrm{W}$ chromosomes as expected, but also in the pericentromeric region of the $\mathrm{Z}$ and $\mathrm{B}$ chromosomes (Fig. 2). Similar results were already described in several organisms demonstrating that supernumerary and the main set of chromosomes often share sequences, e.g., Astyanax scabripinnis (Jenyns, 1842) (Mestriner et al. 2000), Prochilodus lineatus (Valenciennes, 1836) (Jesus et al. 2003), Podisma sapporensis Shiraki, 1910 (Bugrov et al. 2004), Apodemus peninsulae (Thomas, 1907) (Rubtsov et al. 2004), Locusta migratoria (L., 1758) (Teruel et al. 2009). These results point either to a common origin for these genomic elements, to an evolutionary correlation between them or even to the transposition of the shared sequences, given the characteristic mobility of some of the repetitive fractions of the genome.

The correlation between B and sex chromosomes has also been significantly reported in insect (e.g., Camacho et al. 2011), amphibian (e.g., Green et al. 1993; Sharbel et al. 1998) and fish species (Yoshida et al. 2011). These chromosomes share certain characteristics, such as the differential accumulation of heterochromatin and repetitive DNAs, as well as a lower proportion of active genes, that clearly distinguish them from the autosomes (e.g., Camacho et al. 2011). A particularly interesting case is that of the African cichlid Lithocromis rubripinnis (Seehausen et al. 1998) with B chromosomes apparently derived from the sex chromosome pair and greatly correlated to females (its presence being sex-specific), even though up to that time no sexrelated genes have been identified in the supernumerary chromosomes of this species (Yoshida et al. 2011).

B chromosomes of $C$. cf. gomesi, however, are present in both males and females, without any apparent sex-specific correlation (reviewed in Vicari et al. 2008; Pansonato-Alves et al. 2011). Accordingly, the hypothesis of $\mathrm{B}$ chromosomes in $C$. cf. gomesi originating from sex chromosomes must be considered. The present results demonstrate that $\mathrm{B}$ and sex chromosomes of $C$. cf. gomesi share sequences. The fact that both DCg and CgW4 hybridized only to B and sex chromosomes, and to no other chromosome, can be regarded as a strong indicator of $\mathrm{B}$ chromosomes in this population originating from sex chromosomes since most of the Characidium species with sex chromosomes do not have B chromosomes.

\section{Conclusions}

The process of origin and evolution of sex chromosomes in fishes, especially within the genus Characidium, are not yet fully understood. Several authors propose that the cessation of recombination between the homologous proto-sex chromosomes followed by heterochromaniza- 
tion of the $\mathrm{W}$ or $\mathrm{Y}$ chromosomes constitute the initial steps in the formation of sex chromosomes. In our study, the step of differential heterochromatinization, i.e. the accumulation of repetitive DNA, in the W chromosome is clear in female specimens. This work shows the important role of isolation, characterization and physical mapping of repetitive sequences in providing a better understanding of the composition of the heterochromatin present in the sex chromosomes of Characidium.

\section{Acknowledgements}

We are grateful to Bruno F. Melo, Fábio F. Roxo, Guilherme C. Silva, Jefferson M. Henriques, Luiz H.G. Pereira and Renato Devidé for helping with the fish sampling. We would like to thank Carla Pereira who reviewed and greatly improved the version in English. The financial support for this study was provided by Fundação de Amparo a Pesquisa do Estado de São Paulo (FAPESP-2009/50952-2) and Conselho Nacional de Desenvolvimento Cientifico e Tecnológico (CNPq-240947/2012-6). We also thank the anonymous reviewers for the suggestions.

\section{References}

Bugrov A.G., Karamysheva T.V., Rubtsov D.N., Andreenkova O.V. \& Rubtsov N.B. 2004. Comparative FISH analysis of distribution of $\mathrm{B}$ chromosome repetitive DNA in A and B chromosomes in two subspecies of Podisma sapporensis (Orthoptera, Acrididae). Cytogenet. Genome Res. 106: 284-288. DOI: $10.1159 / 000079300$

Camacho J.P., Schmid M. \& Cabrero J.B. 2011. B Chromosomes and sex in animals. Sex. Dev. 5: 155-166. DOI: $10.1159 / 000324930$

Cermak T., Kubat Z., Hobza R., Koblizkova A., Widmer A., Macas J., Vyskotand B. \& Kejnovsky E. 2008. Survey of repetitive sequences in Silene latifolia with respect to their distribution on sex chromosomes. Chromosome Res. 16: 961976. DOI: $10.1007 / \mathrm{s} 10577-008-1254-2$

Charlesworth D., Charlesworth B. \& Marais G. 2005. Steps in the evolution of heteromorphic sex chromosomes. Heredity 95: $118-128$. DOI: $10.1038 /$ sj.hdy. 6800697

Cioffi M.B., Camacho J.P.M. \& Bertollo L.A.C. 2011. Repetitive DNAs and differentiation of sex chromosomes in Neotropical fishes. Cytogenet. Genome Res. 132: 188-194. DOI: $10.1159 / 000321571$

Cioffi M.B., Moreira-Filho O., Almeida-Toledo L.F. \& Bertollo L.A.C. 2012. The contrasting role of heterochromatin in the differentiation of sex chromosomes: an overview from Neotropical fishes. J. Fish Biol. 80: 2125-2139. DOI: 10.1111/ j.1095-8649.2012.03272.x

Ferreira D.C. Porto-Foresti F., Oliveira C. \& Foresti F. 2011. Transposable elements as a potential source for understanding the fish genome. Mobile Genetic Elements 1: 1-6. DOI: 10.4161/mge.1.2.16731

Foresti F., Almeida-Toledo L.F. \& Toledo S.A. 1981. Polymorphic nature of nucleolus organizer regions in fishes. Cytogenet. Cell Genet. 31(3): 137-144. PMID: 6173166

Fuková I., Traut W., Vítková M., Nguyen P., Kubíčková S. \& Marec F. 2007. Probing the W chromosome of the codling moth, Cydia pomonella, with sequences from microdissected sex chromatin. Chromosoma 116: $135-145$. DOI: 10.1007/s00412-006-0086-0

Green D.M., Zeyl C.W. \& Sharbel T.F. 1993. The evolution of hypervariable sex and supernumerary (B) chromosomes in the relict New Zealand frog, Leiopelma hochstetteri. J. Evol. Biol. 6: 417-441. DOI: 10.1046/j.1420-9101.1993.6030417.x
Jesus C.M., Galetti P.M., Valentini S.R. \& Moreira-Filho O. 2003. Molecular characterization and chromosomal localization of two families of satellite DNA in Prochilodus lineatus (Pisces, Prochilodontidae), a species with B chromosomes. Genetica 118: 25-32. DOI: 10.1023/A:1022986816648

Kejnovsky E., Hobza R., Cermák T., Kubát Z. \& Vyskot B. 2009. The role of repetitive DNA in structure and evolution of sex chromosomes in plants. Heredity 102: $533-541$. DOI: 10.1038/hdy.2009.17

Machado T.C., Pansonato-Alves J.C., Pucci M.B., Nogaroto V., Almeida M.C., Oliveira C., Foresti F., Bertollo L.A.C., Moreira-Filho O., Artoni R.F. \& Vicari M.R. 2011. Chromosomal painting and ZW sex chromosomes differentiation in Characidium (Characiformes, Crenuchidae). BMC Genet. 12: 65 . DOI: $10.1186 / 1471-2156-12-65$

Matsubara K., Tarui H., Toriba M., Yamada K., Umehara C.N. Agata K. \& Matsuda Y. 2006. Evidence for different origin of sex chromosomes in snakes, birds, and mammals and stepwise differentiation of snake sex chromosomes. Proc. Natl. Acad. Sci. USA 103: 18190-18195. DOI: 10.1073/pnas.0605274103

Mestriner C.A., Galetti P.M., Valentini S.R., Ruiz, I.R.G., Abel L.D.S., Moreira-Filho O. \& Camacho J.P.M. 2000. Structural and functional evidence that a $\mathrm{B}$ chromosome in the characid fish Astyanax scabripinnis is an isochromosome. Heredity 85: 1-9. DOI: $10.1046 /$ j.1365-2540.2000.00702.x

Nakayama I., Foresti F., Tewari R., Schartl M. \& Chourrout D. 1994. Sex chromosome polymorphism and heterogametic males revealed by two cloned DNA probes in the $\mathrm{ZW} / \mathrm{ZZ}$ fish Leporinus elongatus. Chromosoma 103: 31-39. DOI: 10.1007/BF00364723

Nanda I., Feichtinger W., Schmid M., Schröder J.H., Zischler H. \& Epplen, J.T. 1990. Simple repetitive sequences are associated with differentiation of the sex chromosomes in the guppy fish. J. Mol. Evol. 30: 456-462. DOI: 10.1007/BF02101117

Nanda I., Volff J.N., Weis S., Korting C., Froschauer A., Schimid M. \& Schartl M. 2000. Amplification of a long terminal repeat-like element on the $\mathrm{Y}$ chromosome of the platyfish, Xiphophorus maculatus. Chromosoma 109: 173-180. DOI: $10.1007 / \mathrm{s} 004120050425$

Pansonato-Alves J.C., Vicari M.R., Oliveira C. \& Foresti F. 2011. Chromosomal diversification in populations of Characidium cf. gomesi (Teleostei: Crenuchidae). J. Fish Biol. 78: 183-194. DOI: $10.1111 / \mathrm{j} .1095-8649.2010 .02847 . x$.

Parise-Maltempi P.P., Martins C., Oliveira C. \& Foresti F. 2007. Identification of a new repetitive element in the sex chromosomes of Leporinus elongatus (Teleostei: Characiformes: Anostomidae): new insights into the sex chromosomes of Leporinus. Cytogenet. Genome Res. 116: 218-223. DOI: $10.1159 / 000098190$

Pazian M.F., Shimabukuro-Dias C.K., Pansonato-Alves J.C., Oliveira C. \& Foresti F. 2013. Chromosome painting of Z and $\mathrm{W}$ sex chromosomes in Characidium (Characiformes, Crenuchidae). Genetica 141: 1-9. DOI: 10.1007/s10709-0139701-1.

Pinkel D., Straume T. \& Gray J.W. 1986. Cytogenetic analysis using quantitative, high sensitivity, fluorescence hybridization. Proc. Natl. Acad. Sci. USA 83: 2934-2938. PMCID: PMC323421

Poulter R.T., Goodwin T.J. \& Butler M.I. 2003. Vertebrate helentrons and other novel Helitrons. Gene 313: 201-212. DOI: 10.1016/S0378-1119(03)00679-6

Rubtsov N.B., Karamysheva T.V., Andreenkova O.V., Bochkaerev M.N., Kartavtseva I.V., Roslik G.V. \& Borissov Y.M. 2004. Comparative analysis of micro and macro B chromosomes in the Korean field mouse Apodemus peninsulae (Rodentia, Murinae) performed by chromosome microdissection and FISH. Cytogenet Genome Res. 106: 289-294. DOI: 10.1159/000079301

Sharbel T.F., Green D.M. \& Houben A. 1998. B-chromosome origin in the endemic New Zealand frog Leiopelma hochstetteri through sex chromosome evolution. Genome 41(1): 14-22. DOI: $10.1139 / \mathrm{g} 97-091$ 
Steinemann M. \& Steinemann S. 1992. Degenerating Y chromosome of Drosophila miranda: a trap for retrotransposons. Proc. Natl. Acad. Sci. USA 89: 7591-7595. DOI: 10.1073/pnas.89.16.7591

Sumner A.T. 1972. A simple technique for demonstrating centromeric heterochromatin. Exp. Cell Res. 75: 304-306. DOI: 10.1016/0014-4827(72)90558-7

Takehana Y., Naruse K., Asada Y., Matsuda Y., Shin I.T., Kohara Y., Fujiyama A., Hamaguchi S. \& Sakaizumi M. 2012. Molecular cloning and characterization of the repetitive DNA sequences that comprise the constitutive heterochromatin of the W chromosomes of medaka fishes. Chromosome Res. 20: 71-81. DOI: $10.1007 / \mathrm{s} 10577-011-9259-7$

Teruel M., Cabrero J., Montiel E.E., Acosta M.J., Sánchez A. \& Camacho J.P.M. 2009. Microdissection and chromosome painting of $\mathrm{X}$ and $\mathrm{B}$ chromosomes in Locusta migratoria. Chromosome Res. 17: 11-18. DOI: 10.1007/s10577-008-9001-2

Vicari M.R., Artoni R.F., Moreira-Filho O. \& Bertollo L.A.C. 2008. Diversification of a $\mathrm{ZZ/ZW} \mathrm{sex} \mathrm{chromosome} \mathrm{system}$ in Characidium fish (Crenuchidae, Characiformes). Genetica 134: 311-317. DOI: 10.1007/s10709-007-9238-2
Vicente V.E., Bertollo L.A.C., Valentini, S.R. \& Moreira-Filho O. 2003. Origin and differentiation of sex chromosome system in Parodon hilarii (Pisces, Parodontidae) satellite DNA, G and C-banding. Genetica 119: 115-120. DOI: 10.1023/A:1026082904672

Volff J.N., Nanda I., Schmid M. \& Schartl M. 2007. Governing sex determination in fgish: Regulatory putsches and ephemeral dictators. Sex. Dev. 1: 85-99. DOI: 10.1159/000100030

Yoshida K., Terai Y., Mizoiri S., Aibara M., Nishihara H., Watanabe M., Kuroiwa A., Hirai H., Hirai Y., Matsuda Y. \& Okada N. 2011. B Chromosomes have a functional effect on female sex determination in Lake Victoria cichlid fishes. PLoS Genet. 7: e1002203. DOI: 10.1371/journal.pgen.1002203

Zhou Q., Froschauer A., Schultheis C., Schmidt C., Bienert G.P., Wenning M., Dettai A. \& Volff J.N. 2006. Helitron transposons on the sex chromosomes of the platyfish Xiphophorus maculatus and their evolution in animal genomes. Zebrafish 3: 39-52. DOI: 10.1089/zeb.2006.3.39

Received April 28, 2014 Accepted July 10, 2014 